\title{
The Financial Crisis and the Systemic Failure of Academic Economics*
}

\author{
David Colander, \\ Department of Economics \\ Middlebury College \\ Middlebury, VE, USA \\ Armin Haas \\ Department of Mathematics \\ Humboldt University Berlin \\ Berlin, Germany \\ Michael Goldberg \\ Potsdam Institute for Climate Impact Research \\ Potsdam, Germany
Whittemore School of Business \& Economics
University of New Hampshire
Durham, NH, USA \\ Katarina Juselius \\ Department of Economics \\ University of Copenhagen \\ Copenhagen, Denmark
GREQAM, Université d'Aix-Marseille lll, EHESS et IUF
Marseille, France
Brigitte Sloth
Department of Business and Economics
University of Southern Denmark
Odense, Denmark \\ Alan Kirman \\ Thomas Lux ${ }^{1}$ \\ Department of Economics \\ University of Kiel \\ \& \\ Kiel Institute for the World Economy \\ Kiel, Germany
}

Abstract: The economics profession appears to have been unaware of the long build-up to the current worldwide financial crisis and to have significantly underestimated its dimensions once it started to unfold. In our view, this lack of understanding is due to a misallocation of research efforts in economics. We trace the deeper roots of this failure to the profession's insistence on constructing models that, by design, disregard the key elements driving outcomes in real-world markets. The economics profession has failed in communicating the limitations, weaknesses, and even dangers of its preferred models to the public. This state of affairs makes clear the need for a major reorientation of focus in the research economists undertake, as well as for the establishment of an ethical code that would ask economists to understand and communicate the limitations and potential misuses of their models.

Keywords: financial crisis, academic moral hazard, ethic responsibility of researchers

* This opinion paper is the outcome of one week of intense discussions within the working group on 'Modeling of Financial Markets' at the $98^{\text {th }}$ Dahlem Workshop, 2008. We are grateful to Carlo Jaeger and Rupert Klein for organizing this stimulating meeting and to Deirdre McCloskey and other participants for helpful comments.

\footnotetext{
${ }^{1}$ Corresponding author: Address: University of Kiel, Department of Economics, Olshausenstraße 40

D-24118 Kiel, lux@bwl.uni-kiel.de
} 


\section{Introduction}

The global financial crisis has revealed the need to rethink fundamentally how financial systems are regulated. It has also made clear a systemic failure of the economics profession. Over the past three decades, economists have largely developed and come to rely on models that disregard key factors-including heterogeneity of decision rules, revisions of forecasting strategies, and changes in the social context-that drive outcomes in asset and other markets. It is obvious, even to the casual observer that these models fail to account for the actual evolution of the real-world economy. Moreover, the current academic agenda has largely crowded out research on the inherent causes of financial crises. There has also been little exploration of early indicators of system crisis and potential ways to prevent this malady from developing. In fact, if one browses through the academic macroeconomics and finance literature, "systemic crisis" appears like an otherworldly event that is absent from economic models. Most models, by design, offer no immediate handle on how to think about or deal with this recurring phenomenon. ${ }^{2}$ In our hour of greatest need, societies around the world are left to grope in the dark without a theory. That, to us, is a systemic failure of the economics profession.

The implicit view behind standard models is that markets and economies are inherently stable and that they only temporarily get off track. The majority of economists thus failed to warn policy makers about the threatening system crisis and ignored the work of those who did. Ironically, as the crisis has unfolded, economists have had no choice but to abandon their standard models and to produce hand-waving common-sense remedies. Common-sense advice, although useful, is a poor substitute for an underlying model that can provide much-needed guidance for developing policy and regulation. It is not enough to put the existing model to one side, observing that one needs, "exceptional measures for exceptional times". What we need are models capable of envisaging such "exceptional times”.

The confinement of macroeconomics to models of stable states that are perturbed by limited external shocks and that neglect the intrinsic recurrent boom-and-bust dynamics of our economic system is remarkable. After all, worldwide financial and economic crises are hardly new and they have had a tremendous impact beyond the immediate economic consequences of mass unemployment and hyper inflation. This is even more surprising, given the long academic legacy of earlier economists' study of crisis phenomena, which can be found in the work of Walter Bagehot (1873), Axel Leijonhuvfud (2000), Charles

\footnotetext{
${ }^{2}$ Reinhart and Rogoff (2008) argue that the current financial crisis differs little from a long chain of similar crises in developed and developing countries. We certainly share their view. The problem is that the received body of models in macro finance to which these authors have prominently contributed provides no room whatsoever for such recurrent boom and bust cycles. The literature has, therefore, been a major source of the illusory 'this time it is different' view that the authors themselves criticize.
} 
Kindleberger (1989), and Hyman Minsky (1986), to name a few prominent examples. This tradition, however, has been neglected and even suppressed.

The most recent literature provides us with examples of blindness against the upcoming storm that seem odd in retrospect. For example, in their analysis of the risk management implications of CDOs, Krahnen (2005) and Krahnen and Wilde (2006) mention the possibility of an increase of 'systemic risk.' But, they conclude that this aspect should not be the concern of the banks engaged in the CDO market, because it is the governments' responsibility to provide costless insurance against a system-wide crash. On the more theoretical side, a recent and prominent strand of literature essentially argues that consumers and investors are too risk averse because of their memory of the (improbable) event of the Great Depression (e.g., Cogley and Sargent, 2008). Much of the motivation for economics as an academic discipline stems from the desire to explain phenomena like unemployment, boom and bust cycles, and financial crises, but the dominant theoretical model excludes many of the aspects of the economy that will likely lead to a crisis. Confining theoretical models to 'normal' times without consideration of such defects might seem contradictory to the focus that the average taxpayer would expect of the scientists on his payroll.

This failure has deep methodological roots. The often heard definition of economics - that it is concerned with the 'allocation of scarce resources'-is short-sighted and misleading. It reduces economics to the study of optimal decisions in well-specified choice problems. Such research generally loses track of the inherent dynamics of economic systems and the instability that accompanies its complex dynamics. Without an adequate understanding of these processes, one is likely to miss the major factors that influence the economic sphere of our societies. ${ }^{3}$ The inadequate definition of economics often leads researchers to disregard questions about the coordination of actors and the possibility of coordination failures. Indeed, analysis of these issues would require a different type of mathematics than that which is generally used now by many prominent economic models.

Many of the financial economists who developed the theoretical models upon which the modern financial structure is built were well aware of the strong and highly unrealistic restrictions imposed on their models to assure stability. Yet, financial economists gave little warning to the public about the fragility of their models; ${ }^{4}$ even as they saw individuals and businesses build a financial system based on their work. There are a number of possible explanations for this failure to warn the public. One is a "lack of understanding"

\footnotetext{
${ }^{3}$ For example, the German members of this group of authors share a vivid memory of a prominent economic adviser in their country elaborating very recently on the supposed importance of extending shopping times to increase 'efficiency,' presumably unaware of the major crisis (and the source of major inefficiencies) that was already looming as he spoke.

${ }^{4}$ Indeed, few researchers explored the consequences of a breakdown of their assumptions, even though this was rather likely.
} 
explanation--the researchers did not know the models were fragile. We find this explanation highly unlikely; financial engineers are extremely bright, and it is almost inconceivable that such bright individuals did not understand the limitations of the models. A second, more likely explanation, is that they did not consider it their job to warn the public. If that is the cause of their failure, we believe that it involves a misunderstanding of the role of the economist, and involves an ethical breakdown. In our view, economists, as with all scientists, have an ethical responsibility to communicate the limitations of their models and the potential misuses of their research. Currently, there is no ethical code for professional economic scientists. There should be one.

In the following pages, we identify some major areas of concern in theory and applied methodology and point out their connection to crisis phenomena. We also highlight some promising avenues of study that may provide guidance for future researchers.

\section{Models (or the Use of Models) as a Source of Risk}

The economic textbook models applied for allocation of scarce resources are predominantly of the Robinson Crusoe (representative agent) type. Financial market models are obtained by letting Robinson manage his financial affairs as a sideline to his well-considered utility maximization over his (finite or infinite) expected lifespan taking into account with correct probabilities all potential future happenings. This approach is mingled with insights from Walrasian general equilibrium theory, in particular the finding of the Arrrow-Debreu two-period model that all uncertainty can be eliminated if only there are enough contingent claims (i.e., appropriate derivative instruments). This theoretical result (a theorem in an extremely stylized model) underlies the belief shared by many economists that the introduction of new classes of derivatives can only be welfare increasing (a view obviously originally shared by former Fed Chairman Greenspan). It is worth emphasizing that this view is not an empirically grounded belief but an opinion derived from a benchmark model that is much too abstract to be confronted with data.

On the practical side, mathematical portfolio and risk management models have been the academic backbone of the tremendous increase of trading volume and diversification of instruments in financial markets. Typically, new derivative products achieve market penetration only if a certain industry standard has been established for pricing and risk management of these products. Mostly, pricing principles are derived from a set of assumptions on an 'appropriate' process for the underlying asset, (i.e., the primary assets on which options or forwards are written) together with an equilibrium criterion such as arbitrage-free prices. With that mostly comes advice for hedging the inherent risk of a derivative position by balancing it with other assets that neutralize the risk exposure. The most prominent example is certainly the development of a theory of option pricing by Black and Scholes that eventually (in the eighties) could even be implemented on pocket 
calculators. Simultaneously with Black-Scholes option pricing, the same principles led to the widespread introduction of new strategies under the heading of portfolio insurance and dynamic hedging that just tried to implement a theoretically risk-free portfolio composed of both assets and options and keep it risk-free by frequent rebalancing after changes of its input data (e.g., asset prices). For structured products for credit risk, the basic paradigm of derivative pricing - perfect replication - is not applicable so that one has to rely on a kind of rough-and-ready evaluation of these contracts on the base of historical data.

Unfortunately, historical data were hardly available in most cases which meant that one had to rely on simulations with relatively arbitrary assumptions on correlations between risks and default probabilities. This makes the theoretical foundations of all these products highly questionable - the equivalent to building a building of cement of which you weren't sure of the components. The dramatic recent rise of the markets for structured products (most prominently collateralized debt obligations and credit default swaps - CDOs and CDSs) was made possible by development of such simulation-based pricing tools and the adoption of an industry-standard for these under the lead of rating agencies. Barry Eichengreen (2008) rightly points out that the "development of mathematical methods designed to quantify and hedge risk encouraged commercial banks, investment banks and hedge funds to use more leverage" as if the very use of the mathematical methods diminished the underlying risk. He also notes that the models were estimated on data from periods of low volatility and thus could not deal with the arrival of major changes. Worse, it is our contention that such major changes are endemic to the economy and cannot be simply ignored.

What are the flaws of the new unregulated financial markets which have emerged? As we have already pointed out in the introduction, the possibility of systemic risk has not been entirely ignored but it has been defined as lying outside the responsibility of market participants. In this way, moral hazard concerning systemic risk has been a necessary and built-in attribute of the system. The neglect of the systemic part in the 'normal mode of operation', of course, implies that external effects are not taken properly into account and that in tendency, market participants will ignore the influence of their own behavior on the stability of the system. The interesting aspect is more that this was a known and accepted element of operations. Note that the blame should not only fall on market participants, but also on the deliberate ignoring of the systemic risk factors or the failure to at least point them out to the public amounts to a sort of academic 'moral hazard'.

There are some additional aspects as well: asset-pricing and risk management tools are developed from an individualistic perspective, taking as given (ceteris paribus) the behavior of all other market participants. However, popular models might be used by a large number or even the majority of market participants. Similarly, a market participant (e.g., the notorious Long-Term Capital Management) might become so dominant in certain markets that the ceteris paribus assumption becomes unrealistic. The simultaneous pursuit 
of identical micro strategies leads to synchronous behavior and mechanic contagion. This simultaneous application might generate an unexpected macro outcome that actually jeopardizes the success of the underlying micro strategies. A perfect illustration is the U.S. stock market crash of October 1987. Triggered by a small decrease of prices, automated hedging strategies produced an avalanche of sell orders that out of the blue led to a fall in U.S. stock indices of about 20 percent within one day. With the massive sales to rebalance their portfolios (along the lines of Black and Scholes), the relevant actors could not realize their attempted incremental adjustments, but rather suffered major losses from the ensuing large macro effect.

A somewhat different aspect is the danger of a control illusion: The mathematical rigor and numerical precision of risk management and asset pricing tools has a tendency to conceal the weaknesses of models and assumptions to those who have not developed them and do not know the potential weakness of the assumptions and it is indeed this that Eichengreen emphasizes. Naturally, models are only approximations to the real world dynamics and partially built upon quite heroic assumptions (most notoriously: Normality of asset price changes which can be rejected at a confidence level of 99. 9999.... Anyone who has attended a course in first-year statistics can do this within minutes). Of course, considerable progress has been made by moving to more refined models with, e.g., 'fat-tailed' Levy processes as their driving factors. However, while such models better capture the intrinsic volatility of markets, their improved performance, taken at face value, might again contribute to enhancing the control illusion of the naïve user.

The increased sophistication of extant models does, however, not overcome the robustness problem and should not absolve the modelers from explaining their limitations to the users in the financial industry. As in nuclear physics, the tools provided by financial engineering can be put to very different uses so that what is designed as an instrument to hedge risk can become a weapon of 'financial mass destruction' (in the words of Warren Buffet) if used for increased leverage. In fact, it appears that derivative positions have been built up often in speculative ways to profit from high returns as long as the downside risk does not materialize. Researchers who develop such models can claim they are neutral academics developing tools that people are free to use or not. We do not find that view credible.

Researchers have an ethical responsibility to point out to the public when the tool that they developed is misused. It is the responsibility of the researcher to make clear from the outset the limitations and underlying assumptions of his models and warn of the dangers of their mechanic application.

What follows from our diagnosis? Market participants and regulators have to become more sensitive towards the potential weaknesses of risk management models. Since we do not know the 'true' model, robustness should be a key concern. Model uncertainty should be taken into account by applying more than a single model. For example, one could rely on 
probabilistic projections that cover a whole range of specific models (cf., Föllmer, 2008). The theory of robust control provides a toolbox of techniques that could be applied for this purpose, and it is an approach that should be considered.

\section{Unrealistic Model Assumptions and Unrealistic Outcomes}

Many economic models are built upon the twin assumptions of 'rational expectations' and a representative agent. 'Rational expectations' forces individuals' expectations into harmony with the structure of the economist's own model. This concept can be thought of as merely a way to close a model. A behavioral interpretation of rational expectations would imply that individuals and the economist have a complete understanding of the economic mechanisms governing the world. In this sense, rational expectations models do not formalize expectations as such: they are not written down as a component of the model according to some empirical observation of the expectation formation of human actors. Thus, even when applied economics research or psychology provide insights about how individuals actually form expectations, these insights cannot be used within RE models. Leaving no place for imperfect knowledge and adaptive adjustments, rational expectations models are typically found to have dynamics that are not smooth enough to fit economic data well.

Technically, rational expectations models are often framed as dynamic programming problems in macroeconomics. But, dynamic programming models have serious limitations. Specifically, to make them analytically tractable, researchers assume representative agents and rational expectations, which assume away any heterogeneity among economic actors. Such models presume that there is a single model of the economy, which is odd given that even economists are divided in their views about the correct model of the economy. While other currents of research do exist, economic policy advice, particularly in financial economics, has far too often been based (consciously or not) on a set of axioms and hypotheses derived ultimately from a highly limited dynamic control model, using the Robinson approach with 'rational' expectations.

The major problem is that despite its many refinements, this is not at all an approach based on, and confirmed by, empirical research. ${ }^{5}$ In fact, it stands in stark contrast to a broad set of regularities in human behavior discovered both in psychology and what is called behavioral and experimental economics. The corner stones of many models in finance and macroeconomics are rather maintained despite all the contradictory evidence discovered in

\footnotetext{
${ }^{5}$ The historical emergence of the representative agent paradigm is a mystery. Ironically, it appeared over the 70s after a period of intense discussions on the problem of aggregation in economics (that basically yielded negative results such as the impossibility to demonstrated 'nice' properties of aggregate demand or supply functions without imposing extreme assumptions on individual behavior). The representative agent appeared without methodological discussion. In the words of Deirdre McCloskey: "It became a rule in the conversation of some economists because Tom and Bob said so." (personal communication). Today, this convention has become so strong that many young economists wouldn't know of an alternative way to approach macroeconomic issues.
} 
empirical research. Much of this literature shows that human subjects act in a way that bears no resemblance to the rational expectations paradigm and also have problems discovering 'rational expectations equilibria' in repeated experimental settings. Rather, agents display various forms of 'bounded rationality' using heuristic decision rules and displaying inertia in their reaction to new information. They have also been shown in financial markets to be strongly influenced by emotional and hormonal reactions (see Lo et al., 2005, and Coates and Herbert, 2008) Economic modeling has to take such findings seriously.

What we are arguing is that as a modeling requirement, internal consistency must be complemented with external consistency: Economic modeling has to be compatible with insights from other branches of science on human behavior. It is highly problematic to insist on a specific view of humans in economic settings that is irreconcilable with evidence.

The 'representative agent' aspect of many current models in macroeconomics (including macro finance) means that modelers subscribe to the most extreme form of conceptual reductionism (Lux and Westerhoff, 2009): by assumption, all concepts applicable to the macro sphere (i.e., the economy or its financial system) are fully reduced to concepts and knowledge for the lower-level domain of the individual agent. It is worth emphasizing that this is quite different from the standard reductionist concept that has become widely accepted in natural sciences. The more standard notion of reductionism amounts to an approach to understanding the nature of complex phenomena by reducing them to the interactions of their parts, allowing for new, emergent phenomena at the higher hierarchical level (the concept of 'more is different', cf. Anderson, 1972).

Quite to the contrary, the representative agent approach in economics has simply set the macro sphere equal to the micro sphere in all respects. One could, indeed, say that this concept negates the existence of a macro sphere and the necessity of investigating macroeconomic phenomena in that it views the entire economy as an organism governed by a universal will. ${ }^{6}$ Any notion of "systemic risk" or "coordination failure" is necessarily absent from, and alien to, such a methodology.

For natural scientists, the distinction between micro-level phenomena and those originating on a macro, system-wide scale from the interaction of microscopic units is well-known. In a dispersed system, the current crisis would be seen as an involuntary emergent phenomenon of the microeconomic activity. The conceptual reductionist paradigm, however, blocks from the outset any understanding of the interplay between the micro and macro levels. The differences between the overall system and its parts remain

\footnotetext{
${ }^{6}$ The conceptual reductionist approach of the representative agent is also remarkably different from the narrative of the 'invisible hand' which has more the flavor of 'more is different'.
} 
simply incomprehensible from the viewpoint of this approach.

In order to develop models that allow us to deduce macro events from microeconomic regularities, economists have to rethink the concept of micro foundations of macroeconomic models. Since economic activity is of an essentially interactive nature, economists' micro foundations should allow for the interactions of economic agents. Since interaction depends on differences in information, motives, knowledge and capabilities, this implies heterogeneity of agents. For instance, only a sufficiently rich structure of connections between firms, households and a dispersed banking sector will allow us to get a grasp on "systemic risk", domino effects in the financial sector, and their repercussions on consumption and investment. The dominance of the extreme form of conceptual reductionism of the representative agent has prevented economists from even attempting to model such all important phenomena. It is the flawed methodology that is the ultimate reason for the lack of applicability of the standard macro framework to current events.

Since most of what is relevant and interesting in economic life has to do with the interaction and coordination of ensembles of heterogeneous economic actors, the methodological preference for single actor models has extremely handicapped macroeconomic analysis and prevented it from approaching vital topics. For example, the recent surge of research in network theory has received relatively scarce attention in economics. Given the established curriculum of economic programs, an economist would find it much more tractable to study adultery as a dynamic optimization problem of a representative husband, and derive the optimal time path of marital infidelity (and publish his exercise) rather than investigating financial flows in the banking sector within a network theory framework. This is more than unfortunate in view of the network aspects of interbank linkages that have become apparent during the current crisis.

In our view, a change of focus is necessary that takes seriously the regularities in expectation formation revealed by behavioral research and, in fact, gives back an independent role to expectations in economic models. It would also be fallacious to only replace the current paradigm by a representative 'non-rational' actor (as it is sometimes done in recent literature). Rather, an appropriate micro foundation is needed that considers interaction at a certain level of complexity and extracts macro regularities (where they exist) from microeconomic models with dispersed activity.

Once one acknowledges the importance of empirically based behavioral micro foundations and the heterogeneity of actors, a rich spectrum of new models becomes available. The dynamic co-evolution of expectations and economic activity would allow one to study out-of-equilibrium dynamics and adaptive adjustments. Such dynamics could reveal the possibility of multiplicity and evolution of equilibria (e.g. with high or low employment) depending on agents' expectations or even on the propagation of positive or negative 
'moods' among the population. This would capture the psychological component of the business cycle which - though prominent in many policy-oriented discussions - is never taken into consideration in contemporary macroeconomic models.

It is worth noting that understanding the formation of such low-level equilibria might be much more valuable in coping with major 'efficiency losses' by mass unemployment than the pursuit of small 'inefficiencies' due to societal decisions on norms such as shop opening times. Models with interacting heterogeneous agents would also open the door to the incorporation of results from other fields: network theory has been mentioned as an obvious example (for models of networks in finance see Allen and Babus, 2008). 'Self-organized criticality' theory is another area that seems to have some appeal for explaining boom-and-bust cycles (cf. Scheinkman and Woodford, 1992). Incorporating heterogeneous agents with imperfect knowledge would also provide a better framework for the analysis of the use and dissemination of information through market operations and more direct links of communication. If one accepts that the dispersed economic activity of many economic agents could be described by statistical laws, one might even take stock of methods from statistical physics to model dynamic economic systems (cf. Aoki and Yoshikawa, 2007; Lux, 2009, for examples).

\section{Robustness and Data-Driven Empirical Research}

Currently popular models (in particular: dynamic general equilibrium models) do not only have weak micro foundations, their empirical performance is far from satisfactory (Juselius and Franchi, 2007). Indeed, the relevant strand of empirical economics has more and more avoided testing their models and has instead turned to calibration without explicit consideration of goodness-of-fit. ${ }^{7}$ This calibration is done using "deep economic parameters" such as parameters of utility functions derived from microeconomic studies. However, at the risk of being repetitive, it should be emphasized that micro parameters cannot be used directly in the parameterization of a macroeconomic model. The aggregation literature is full of examples that point out the possible "fallacies of composition". The "deep parameters" only seem sensible if one considers the economy as a universal organism without interactions. If interactions are important (as it seems to us they are), the restriction of the parameter space imposed by using micro parameters is inappropriate.

Another concern is nonstationarity and structural shifts in the underlying data. Macro models, unlike many financial models, are often calibrated over long time horizons which include major changes in the regulatory framework of the countries investigated. Cases in

\footnotetext{
${ }^{7}$ It is pretty obvious how the currently popular class of dynamic general equilibrum models would have to 'cope' with the current financial crisis. It will be covered either by a dummy or it will have to be interpreted as a very large negative stochastic shock to the economy, i.e. as an event equivalent to a large asteroid strike.
} 
question are the movements between different exchange rate regimes and the deregulation of financial markets over the 70s and 80s. In summary, it seems to us that much of contemporary empirical work in macroeconomics and finance is driven by the pre-analytic belief in the validity of a certain model. Rather than (mis)using statistics as a means to illustrate these beliefs, the goal should be to put theoretical models to scientific test (as the naïve believer in positive science would expect).

The current approach of using pre-selected models is problematic and we recommend a more data-driven methodology. Instead of starting out with an ad-hoc specification and questionable ceteris paribus assumptions, the key features of the data should be explored via data-analytical tools and specification tests. David Hendry provides a well-established empirical methodology for such exploratory data analysis (Hendry, 1995, 2009) as well as a general theory for model selection (Hendry and Krolzig, 2005); clustering techniques such as projection pursuit (e.g. Friedman, 1987) might provide alternatives for the identification of key relationships and the reduction of complexity on the way from empirical measurement to theoretical models. Cointegrated VAR models could provide an avenue towards identification of robust structures within a set of data (Juselius, 2006), for example, the forces that move equilibria (pushing forces, which give rise to stochastic trends) and forces that correct deviations from equilibrium (pulling forces, which give rise to long-run relations). Interpreted in this way, the 'general-to-specific' empirical approach has a good chance of nesting a multivariate, path-dependent data-generating process and relevant dynamic macroeconomic theories. Unlike approaches in which data are silenced by prior restrictions, the Cointegrated VAR model gives the data a rich context in which to speak freely (Hoover et al., 2008).

A chain of specification tests and estimated statistical models for simultaneous systems would provide a benchmark for the subsequent development of tests of models based on economic behavior: significant and robust relations within a simultaneous system would provide empirical regularities that one would attempt to explain, while the quality of fit of the statistical benchmark would offer a confidence band for more ambitious models. Models that do not reproduce (even) approximately the quality of the fit of statistical models would have to be rejected (the majority of currently popular macroeconomic and macro finance models would not pass this test). Again, we see here an aspect of ethical responsibility of researchers: Economic policy models should be theoretically and empirically sound. Economists should avoid giving policy recommendations on the base of models with a weak empirical grounding and should, to the extent possible, make clear to the public how strong the support of the data is for their models and the conclusions drawn from them. 


\section{A Research Agenda to Cope with Financial Fragility}

The notion of financial fragility implies that a given system might be more or less susceptible to produce crises. It seems clear that financial innovations have made the system more fragile. Apparently, the existing linkages within the worldwide, highly connected financial markets have generated the spillovers from the U.S. subprime problem to other layers of the financial system. Many financial innovations had the effect of creating links between formerly unconnected players. All in all, the degree of connectivity of the system has probably increased enormously over the last decades. As is well known from network theory in natural sciences, a more highly connected system might be more efficient in coping with certain tasks (maybe distributing risk components), but will often also be more vulnerable to shocks and - systemic failure! The systematic analysis of network vulnerability has been undertaken in the computer science and operations research literature (see e.g. Criado et al., 2005). Such aspects have, however, been largely absent from discussions in financial economics. The introduction of new derivatives was rather seen through the lens of general equilibrium models: more contingent claims help to achieve higher efficiency. Unfortunately, the claimed efficiency gains through derivatives are merely a theoretical implication of a highly stylized model and, therefore, have to count as a hypothesis. Since there is hardly any supporting empirical evidence (or even analysis of this question), the claimed real-world efficiency gains from derivatives are not justified by true science. While the economic argument in favor of ever new derivatives is more one of persuasion rather than evidence, important negative effects have been neglected. The idea that the system was made less risky with the development of more derivatives led to financial actors taking positions with extreme degrees of leverage and the danger of this has not been emphasized enough.

As we have mentioned, one totally neglected area is the degree of connectivity and its interplay with the stability of the system (see Boesch et al. (2006). We believe that it will be necessary for supervisory authorities to develop a perspective on the network aspects of the financial system, collect appropriate data, define measures of connectivity and perform macro stress testing at the system level. In this way, new measures of financial fragility would be obtained. This would also require a new area of accompanying academic research that looks at agent-based models of the financial system, performs scenario analyses and develops aggregate risk measures. Network theory and the theory of self-organized criticality of highly connected systems would be appropriate starting points.

The danger of systemic risk means that regulation has to be extended from individualistic (regulation of single institutions which of course, is still crucial) to system wide regulation. In the sort of system which is prone to systemic crisis, regulation also has to have a systemic perspective. Academic researchers and supervisory authorities thus have to look into connections within the financial sector and to investigate the repercussions of 
problems within one institute on other parts of the system (even across national borders). Certainly, before deciding about the bail-out of a large bank, this implies an understanding of the network. One should know whether its bankruptcy would lead to widespread domino effects or whether contagion would be limited. It seems to us that what regulators provide currently is far from a reliable assessment of such after effects.

Such analysis has to be supported by more traditional approaches: Leverage of financial institutions rose to unprecedented levels prior to the crisis, partly by evading Basle II regulations through special investment vehicles (SIVs). The hedge fund market is still entirely unregulated. The interplay between leverage, connectivity and system risk needs to be investigated at the aggregate level. It is highly likely, that extreme leverage levels of interconnected institutions will be found to impose unacceptable social risk on the public. Prudent capital requirements would be necessary and would require a solid scientific investigation of the above aspects rather than a pre-analytic laissez-faire attitude.

We also have to re-investigate the informational role of financial prices and financial contracts. While trading in stock markets is usually interpreted as at least in part transmitting information, this information transmission seems to have broken down in the case of structured financial products. It seems that securitization has rather led to a loss of information by anonymous intermediation (often multiple) between borrowers and lenders. In this way, the informational component has been outsourced to rating agencies and typically, the buyer of CDO tranches would not have spent any effort himself on information acquisition concerning his far away counterparts. However, this centralized information processing instead of the dispersed one in traditional credit relationships might lead to a severe loss of information. As it turned out, standard loan default models failed dramatically in recent years (Rajan et al, 2008). It should also be noted that the price system itself can exacerbate the difficulties in the financial market (see Hellwig, 2008). One of the reasons for the sharp fall in the asset valuations of major banks was not only the loss on the assets on which their derivatives were based, but also the general reaction of the markets to these assets. As markets became aware of the risk involved, all such assets were written down and it was in this way that a small sector of the market "contaminated" the rest. Large parts of the asset holdings of major banks abruptly lost much of their value. Thus the price system itself can be destabilizing as expectations change.

On the macroeconomic level, it would be desirable to develop early warning schemes that indicate the formation of bubbles. Combinations of indicators with time series techniques could be helpful in detecting deviations of financial or other prices from their long-run averages. Indication of structural change (particularly towards non-stationary trajectories) would be a signature of changes of the behavior of market participants of a bubble-type nature. 


\section{Conclusions}

The current crisis might be characterized as an example of the final stage of a well-known boom-and-bust pattern that has been repeated so many times in the course of economic history. There are, nevertheless, some aspects that make this crisis different from its predecessors: First, the preceding boom had its origin - at least to a large part - in the development of new financial products that opened up new investment possibilities (while most previous crises were the consequence of overinvestment in new physical investment possibilities). Second, the global dimension of the current crisis is due to the increased connectivity of our already highly interconnected financial system. Both aspects have been largely ignored by academic economics. Research on the origin of instabilities, overinvestment and subsequent slumps has been considered as an exotic side track from the academic research agenda (and the curriculum of most economics programs).This, of course, was because it was incompatible with the premise of the rational representative agent. This paradigm also made economics blind with respect to the role of interactions and connections between actors (such as the changes in the network structure of the financial industry brought about by deregulation and introduction of new structured products). Indeed, much of the work on contagion and herding behavior (see Banerjee, 1992, and Chamley, 2002) which is closely connected to the network structure of the economy has not been incorporated into macroeconomic analysis.

We believe that economics has been trapped in a sub-optimal equilibrium in which much of its research efforts are not directed towards the most prevalent needs of society. Paradoxically self-reinforcing feedback effects within the profession may have led to the dominance of a paradigm that has no solid methodological basis and whose empirical performance is, to say the least, modest. Defining away the most prevalent economic problems of modern economies and failing to communicate the limitations and assumptions of its popular models, the economics profession bears some responsibility for the current crisis. It has failed in its duty to society to provide as much insight as possible into the workings of the economy and in providing warnings about the tools it created. It has also been reluctant to emphasize the limitations of its analysis. We believe that the failure to even envisage the current problems of the worldwide financial system and the inability of standard macro and finance models to provide any insight into ongoing events make a strong case for a major reorientation in these areas and a reconsideration of their basic premises. 


\section{References}

Allen, F. and A. Babus, 2008, Networks in Finance. Wharton Financial Institutions Center Working Paper No. 08-07. Available at SSRN: http://ssrn.com/abstract=1094883

Anderson, P.W., 1972, More is different, Science 177, 393-396.

Aoki, M. and H. Yoshikawa, 2007, Reconstructing Macroeconomics: A Perspective from Statistical Physics and Combinatorial Stochastic Processes. Cambridge University Press: Cambridge and New York.

Bagehot, W., 1873, Lombard Street: A Description of the Money Market. Henry S. King and Co.: London.

Banerjee, A., 1992, A simple model of herd behaviour, Quarterly Journal of Economics, 108, 797-817.

Boesch, F. T., F. Harary, and J. A. Kabell, 2006, Graphs as models of communication network vulnerability: Connectivity and persistence, Networks, 11, 57 - 63.

Brigandt, I. and A. Love, 'Reductionism in Biology' in the Stanford Encyclopedia of Philosophy. Available at http://plato.stanford.edu/entries/reduction-biology/

Campos, J., N.R. Ericsson and D.F. Hendry, 2005, Editors' Introduction to General to Specific Modelling, 1 - 81, Edward Elgar: London.

Chamley, C. P., 2002, Rational Herds: Economic Models of Social Learning. Cambridge University Press: Cambridge.

Coates J.M. and J. Herbert, 2008, Endogenous steroids and financial risk taking on a London trading floor, Proceedings of the National Academy of Sciences, 6167 - 6172.

Cogley, T. and T. Sargent, 2008, The market price of risk and the equity premium: A legacy of the Great Depression?, Journal of Monetary Economics, 55, 454-476.

Criado, R., J. Flores, B. Hernández-Bermejo, J. Pello, and M. Romance, 2005, Effective measurement of network vulnerability under random and intentional attacks, Journal of Mathematical Modelling and Algorithms, 4, 307-316.

Eichengreen, B., 2008, Origins and Responses to the Crisis, unpublished manuscript, University of California, Berkeley.

Föllmer, H., 2008, Financial uncertainty, risk measures and robust preferences, in: Yor, M, ed., Aspects of Mathematical Finance, Springer: Berlin. 
Friedman, J., 1987, Exploratory projection pursuit, Journal of the American Statistical Association, 82, 249-266

Hellwig, M. F., 2008, Systemic Risk in the Financial Sector: An Analysis of the Subprime-Mortgage Financial Crisis, MPI Collective Goods Preprint, No. 2008/43.

Hendry, D., 2009, The Methodology of Empirical Econometric Modelling: Applied Econometrics Through the Looking-Glass, forthcoming in The Handbook of Empirical Econometrics, Palgrave.

Hendry, D.F., 1995. Dynamic Econometrics. Oxford University Press: Oxford.

Hendry, D.F. and H-M. Krolzig, 2005, The Properties of Automatic Gets Modelling, Economic Journal, 115, C32--C61.

Hoover, K., S. Johansen, and K. Juselius, 2008, Allowing the data to speak freely: The macroeconometrics of the cointegrated vector autoregression. American Economic Review 98, 251-55.

Juselius, K., 2006, The cointegrated VAR model: Econometric Methodology and Empirical Applications. Oxford University Press: Oxford.

Juselius, K. and M. Franchi, 2007, Taking a DSGE Model to the Data Meaningfully, Economics-The Open-Access, Open-Assessment E-Journal, 4.

Kindleberger, C.P., 1989, Manias, Panics, and Crashes: A History of Financial Crises. MacMillan: London.

Krahnen, J.-P. and C. Wilde, 2006, Risk Transfer with CDOs and Systemic Risk in Banking. Center for Financial Studies, WP 2006-04. Frankfurt.

Krahnen, J.-P., 2005, Der Handel von Kreditrisiken: Eine neue Dimension des Kapitalmarktes Perspektiven der Wirtschaftspolitik 6, 499 - 519.

Leijonhufvud, A., 2000, Macroeconomic Instability and Coordination: Selected Essays, Edward Elgar: Cheltenham.

Lo, A., D. V. Repin and B. N. Steenbarger, Fear and Greed in Financial Markets: A Clinical Study of Day-Traders, American Economic Review 95, 352-359.

Lux, T. and F. Westerhoff, 2009, Economics crisis, Nature Physics 5, 2 - 3.

Lux, T., 2009, Stochastic Behavioral Asset Pricing Models and the Stylized Facts, chapter 3 in T. Hens and K. Schenk-Hoppé, eds., Handbook of Financial Markets: Dynamics and Evolution. North-Holland: Amsterdam,161 - 215.

Minsky, H.P., 1986, Stabilizing an Unstable Economy. Yale University Press: New Haven. 
Rajan, U, A. Seru and V. Vig, 2008, The Failure of Models that Predict Failure: Distance, Incentives and Defaults. Chicago GSB Research Paper No. 08-19.

Reinhart, C. and K. Rogoff, 2008, This Time is Different: A Panoramic View of Eight Centuries of Financial Crises. Manuscript, Harvard University and NBER.

Scheinkman, J. and M. Woodford, 1994, Self-Organized Criticality and Economic Fluctuations, American Economic Review 84 (Papers and Proceedings), 417-421. 